\title{
Eclecticism or Principled Eclecticism
}

\author{
Lianli Gao \\ China Academy of Chinese Medical Sciences, Beijing, China. \\ Email: lianlig@hotmail.com \\ Received May 21 ${ }^{\text {st }}$, 2011; revised June 28 ${ }^{\text {th }}$, 2011; accepted July $5^{\text {th }}, 2011$.
}

\begin{abstract}
The introduction of a new mandatory policy for the teaching of English at the higher education level in China, College English Curriculum Requirements (CECR, published in 2004), had the intention of modernising and improving the quality of English teaching at the tertiary level in China. The policy had a focus on student centred approaches to learning and the use of technology to support this process. This paper reports on a study that investigated the views of teachers, administrators and policy makers about the intended pedagogical shift embedded in the policy and the success of the policy in achieving this goal. The paper attempts to clarify how lecturers in higher education in China have been oriented by the CECR towards pedagogical change. To achieve this purpose, the paper reviews current issues in the context of English teaching at tertiary level in China and attempts to frame them in a conceptualisation of eclecticism and principled eclecticism. Then, the paper analyses the responses of teachers, administrators and policy makers, based on an analysis framework developed by Maton (2004) from the work of Bourdieu (1993) and Bernstein (2000), to uncover the relationship between the policy and the reality. The study found that while teachers are eager to make change themselves, in reality, the requirement of a student centred approach and new technical teaching in the policy, challenges teachers' current knowledge in terms of their current training in understanding curriculum and syllabus, their knowledge of principled eclecticism and computer teaching, and how to deal with textbook teaching and the College English Test. The paper concludes that there is a gap between the policy and reality, and that a gap exists therefore between eclecticism and principled eclecticism in pedagogy in tertiary English teaching in the context of China.
\end{abstract}

Keywords: Eclecticism, Principled Eclecticism, Tertiary English Teaching

\section{Introduction}

One view of English language instruction at university level in China is that Communicative Language Teaching (CLT) has evolved into "eclectic" teaching (Liu \& Dai 2003). The use of an eclectic approach to tertiary English teaching in China was initially described by Luo, He \& Yang (2001). They define the eclectic method not as a concrete, single method, but as a method, which combines listening, speaking, reading, and writing and may include some practice in the classroom. They claim that the current preferred teaching methods are an integration of Grammar-Translation, structural method and CLT and advise teachers to take advantage of all other methods whilst avoiding their disadvantages. They suggest that there are five features of successful eclectic teaching: 1) determine the purposes of each individual method; 2) be flexible in the selection and application of each method; 3) make each method effective; 4) consider the appropriateness of each method and 5) maintain the continuity of the whole teaching process, and divide the operation into three stages: a) teacher-centred at the input stage; b) learner-centred at the practice stage; and c) learner-centred at the production stage. While these opinions are based on their personal experience, they tend to reflect the present thinking of teachers and their confusion over English language teaching theories and practice.

The policy document College English Curriculum Requirements (hereafter referred to as CECR 2004) for teaching English to university students with a non-English major was published in 2004 with the intention of modernising and improving the quality of English teaching. Some aspects of the policy, in terms of teaching methodology, seem to be well considered. Firstly, the document illustrates the basic structure of a suggested model, indicating the role of students and teachers, the content of teaching (five skills) and the model of teaching. It suggests that there are two types of "environments of teaching": self-learning tutoring, which is based on computer-based teaching and regular classroom-based teaching (see Figure 1 below).

In addition, the process of computer-based English learning is also provided, as shown in Figure 2 although there is no further interpretation for why it has been designed this way and how it can be transformed into classroom practice.

The definition of teaching approach (or teaching methodology) does seem to be implicit in the policy. CECR 2004 suggests that a "teaching model" should be built on modern information technology, particularly network technology, so that English language teaching will be free from the constraints of time or place and geared towards students' individualised and autonomous learning. The new model should combine the principles of practicality, knowledge and interest, mobilise the initiative of both teachers and students, and attach particular import-

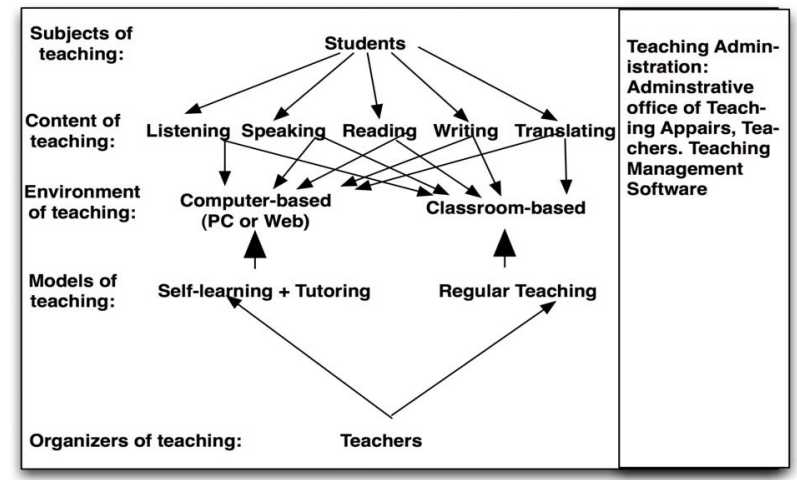

Figure 1.

Computer- and classroom-based teaching (CECR 2004, p. 33 Graph 1). 


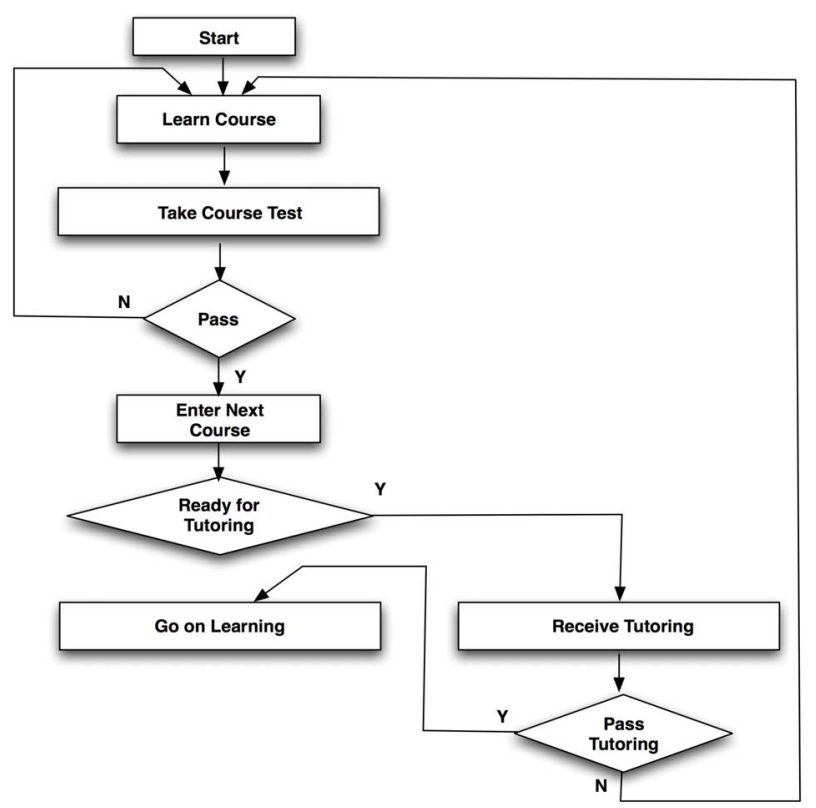

Figure 2.

Process of computer-based English learning (CECR 2004, p. 35 Graph 2).

ance to the central role of students in the teaching and learning process. This model should technically attain a high level of interactivity, feasibility and operability. In addition, it should take into full account and incorporate into it the strengths of the current model, while fully employing modern information technology (CECR 2004: p. 23).

However, there is little explanation of the theoretical rationale underpinning such a model and little guidance as to how such a model might be implemented (CECR 2004: p. 23)

... The new model should enable students to select materials suited to their individual needs, make up for the limitations of the conventional classroom teaching of listening and speaking, and track down, record and check the progress of learning as well as teaching as coaching, ... It is proposed that the credits acquired via computer-based learning account for 30\% - 50\% of the total ( $p .23)$.

This model is technology-oriented with the intention to achieve student autonomous learning. While the model makes heavy demands in its implementation, it does not provide guidance on what is meant in terms of language learning and its related pedagogy, nor does it explain how to achieve students' autonomous learning. Beyond these details, the policy also does not define what "the current model" is. There is no explanation of the theoretical rationale underpinning such a model and little guidance as to how such a model might be implemented.

This lack of detail and depth in the policy does leave open the potential for tertiary teachers to take up the most recent teaching fad, typified by Ma's enthusiasm for techniques in grammar teaching such as "chain story", "the hot seat", or "information transfer” (Ma, 1998: p. 44-46). Such approaches include "the theme teaching model" (Ying et al., 1998) and "the inquiring teaching model” (Liang \& Gao, 2004). For instance, Ying et al. (1998) propose a particular method based on the rather unsurprising findings that teaching reading, writing, listening and speaking, based on the same topic, enlarges students' vocabulary and helps learners master "language points" more easily.

Current tertiary English teaching in China also focuses on introducing overseas teaching methods (Jia, 2004). Jia believes that the purpose for doing so is that "as language teachers, we need to learn something about language teaching, especially to read some books on language teaching approaches and methods by world famous applied linguists, so as to guide our teaching" (2004: p. 74). Yi et al. (2004) advocate the genre approach developed in Australia, "focusing on its assumptions about language teaching and learning, the teaching and learning cycle, and issues in application” (Yi et al., 2004: p. 33).

Such approaches can lead to uncritical adoption of whatever is being promoted at the time by international "experts", rather than basing decisions on a well-considered theoretical position in relation to the Chinese context. Brown (2002) has proposed "principled eclecticism" as a possible way ahead where teachers select what works within their own dynamic contexts based on sound theories and research knowledge.

There has been some research on principled eclecticism in English teaching at university level in China in the past few years, such as the work by Yan, Zhou and Dai (2007) and Wang (2001). The findings of Yan et al. (2007) came from empirical research with a case study. The purpose of their study was to "probe whether the real teaching practice of principled eclecticism was as eclectic and principled as the proponents described at the theoretical level” (2007: p. 2). The study reported that

"eclecticism and principled eclecticism have been widely accepted and practiced with or without the College English teachers" awareness of the methodological issues. What is more, the case study has proved principled eclecticism in IELP in College English teaching to be warmly welcomed by the students and fruitful in effect” (p. 13).

However, there seems to be little information on how the researchers constructed their survey and interview protocols and the paper does not reveal why their analysis is appropriate and reasonable.

While the above discussion sheds light on some of the issues surrounding changes in tertiary English pedagogy in China and the heavy demands required by the eclectic approach, they say nothing about the relationship between the policy and the reality in pedagogy. Additionally, the complicated relationship between the policy and reality in terms of principled eclecticism in tertiary English teaching has not been seriously considered.

In order to investigate this gap in understanding of the current situation in English language teaching in China following the introduction of CECR, the study reported here draws on the responses of teachers, administrators and policy-makers to current challenges of College English Curriculum Requirements 2004. The purpose of the paper is to clarify how lecturers in English teaching at university level have been oriented by the CECR towards pedagogical change. In the context of this paper pedagogical change is considered as being performed in practice and a broad definition of change is assumed. Accordingly, change is interpreted as "a generic term, which subsumes a whole family of concepts such as 'innovation', 'development' and adoption” (Marsh, 2000: p. 380).

In order to achieve this purpose, the study attempts to address the following research questions:

1) What expectations were placed on university teachers of English in relation to principled eclecticism with the introduction of the CECR (2004);

2) What were the responses to these expectations from 
teachers, administrators and policy-makers?

\section{Eclecticism and Principled Eclecticism}

There is a view that the prerequisite for adequate perception of language learning and teaching is to understand theories holistically, with no "black and white" prescription as to teaching approaches. Nunan (1991: p. 228) states that "it has been realised that there never was and probably never will be a method for all”. From the standpoint of critical pedagogy, rather than representing the results of steady, linear progress, Pennycook (1989) believes that current language pedagogy is merely different configurations of the same basic options, which are coloured by dynamic social, political or philosophical factors.

Such complexity gives rise to the question of how teachers are to evaluate the efficacy of the different theories. To address this, Brown (2002) has proposed "principled eclecticism”, where teachers select what works within their own dynamic contexts. Brown claims that principled eclecticism helps language teachers participate in a teaching process of "diagnosis, treatment, and assessment” (Brown, 2002: p. 13). It requires that teachers diagnose proper curricular treatment for learners' needs in their specific context, make effective pedagogical designs for appropriate objectives, and assess accomplishment of curricular objectives (Brown, 2002). Principled eclecticism challenges teachers in that any decision-making must be based on a thorough and holistic understanding of all learning theories and related pedagogies, in terms of the purpose and context of language learning, the needs of the language learners, how language is learned, and how and what teaching is all about (Brown 2002).

To address a similar issue, Kumaravadivelu (2001) provides an organising principle- the pedagogic parameters of particularity, practicality, and possibility - to bring learners, teachers and teacher educators together, in order to construct a postmethod pedagogy. He defines the post-method pedagogy as 1) a focus on a context-sensitive language education based on a true understanding of local linguistic, sociocultural, and political particularities, 2) enabling teachers to construct their own theory of practice, and 3) emphasising the socio-political consciousness, in order to aid the quest for identity formation and social transformation (2001: p. 537). The conceptualising, actualising and problematising of post-method pedagogy reminds us to address the research question in terms of the practices and perceptions of tertiary English teachers in China, in a way that reveals whether their practices and perceptions have changed over time.

Principled eclecticism in this study in the context of English teaching at university level neither simply refers to "the use of a variety of language learning activities, each of which may have very different characteristics" (Mellow, 2002: p. 1) in terms of teachers actions, nor holistically stands for a method searching for a linguistic or sociocultural theory for the context in China. What it does help address is whether teachers are able to know why they do what they do (Larsen Freeman, 2000) in terms of their perceptions of policy in theory and their beliefs in practice.

\section{Research Method and Theoretical Framework}

The issues discussed above need to be addressed with a means of analysing and interpreting appropriate data, rather than simply describing. Maton (2004a) outlines a sophisticated conceptual framework that builds on, integrates and develops the insights of Bourdieu (1993) and Bernstein (2000) within a major study of higher education with concepts such as Autonomy, Specialisation, and Temporality ${ }^{1}$.

The concept of autonomy addresses relations between agents within higher education and other arenas of social practice (Maton, 2004a). Bourdieu (1993) highlights relative autonomy as central to the way a field like higher education is structured and as the key to understanding how external pressures might affect practices within it. Simply put, Maton (2004a) applies Bernstein's notions of classification and framing to this issue of external relations to describe various forms of autonomy. Here two simple modalities are highlighted: stronger autonomy and weaker autonomy. Changes in autonomy, which originate from a new policy (such as CECR 2004) would have a profound effect on the context of TET in China because it would control the nature of change, teachers' perceptions of the change, and the actual practice of teaching in English language classrooms.

A second key concept drawn upon is that of "specialisation". This concerns the basis of claims to insight and legitimacy within the field (Maton, 2004: p. 89). Bourdieu (1993) highlights how educational fields structure education practices by emphasising that each field comprises a "field of positions" (such as an institutional map) and a "field of stances" (such as a disciplinary map). Bernstein (2000) highlights the structuring significance of educational practices for fields by emphasising the underlying principles generating knowledge structures. Maton (2004a) integrates these ideas to establish the ways in which agents and discourses within a field not only are positioned in a structure of knowers (or field of positions) but also in a structure of knowledges (or field of position-takings). Maton suggests that each of these can be more or less emphasised in practice as the basis of what makes someone or something special or worthy of status.

Most important is that Maton (2004: p. 90) points out four modalities for specialisation, among which is a knowledge code emphasising mastery of specialised procedures, techniques or skills and a knower code that emphasises the dispositions of the subject, whether portrayed as "natural" abilities, cultivated sensibilities or resulting from the subject's social position. Specialisation focuses on the issue of the knowledge or the knower. The key issue, for Maton (2004), is whether agents emphasise knowledge and skills, or emphasise the way of thinking and knowing which deals with attitudes and aptitudes. This is important because, for example, if the curriculum changed things from very detailed procedures to very loose procedures with the purpose of affecting attitudes, it would greatly impact upon the way that teachers see themselves and the way that they see their practices. It is significant, therefore, to inform teachers of what the move is (from the knowledge code to knower code or from the knower code to the knowledge code), why the move happens and how the move needs to be coded. This is an important way for teachers to identify themselves and the elements in the field of tertiary English teaching, which closely relate to the teachers themselves.

The final concept drawn upon is "temporality", which deals with the issue of time and change, or more precisely orientation to change (Maton, 2004: p. 92). Bourdieu (1993) emphasises agents' trajectories within a field as central to its structure. Bernstein (2000) suggests we can talk of prospective and retrospective identities when mapping contemporary educational identities by highlighting issues of change and exploring the

${ }^{1}$ In See Maton, K. (2004). The Field of Higher Education: A Sociology of Reproduction, Transformation, Change and the Conditions of Emergence for Cultural Studies. Cambridge: Cambridge University Press. 
temporal orientations of knowledge structures ${ }^{2}$. Maton (2004a) draws on these concepts to talk of codes of temporality and describes two principal modalities: prospective and retrospective. Retrospective temporality refers to established positions in a field whose characterising attributes are based on inheritance from the past. Prospective temporality identifies the attributes that are oriented towards newer forms. In a major study of post-war English higher education, Maton (2004) finds that prospective and retrospective temporalities are the main traditional modalities shaping the field and its change over time.

These three principles provide a simple way of tracing change over time. These concepts are used to "code” Chinese tertiary English teaching in terms of its past policies and practices, contemporary policy changes and the attitudes, and the beliefs and practices of English teachers. This helps to see whether they have changed over time and to perceive the insight into the relations between the policy and the reality in terms of eclecticism and principled eclecticism (Gao, 2010).

The research design adopted here is basically a mixed mode of inquiry, driven by the broader research questions: 1) What expectations were placed on university teachers of English in relation to principled eclecticism with the introduction of the CECR (2004); 2) What were the responses to these expectations from teachers, administrators and policy-makers? The mixed mode inquiry was implemented in two ways: 1) by way of a survey, in order to obtain a wide cross-section of views and information; and 2) through individual interviews, in order to explore issues in greater depth ${ }^{3}$. Policy statements and teachers' responses were examined giving rise to questions such as how policy was implemented and what were teacher's general perceptions and practices in response to these documents.

To answer the research questions, a semi-structured survey instrument, with Likert scale was constructed, trialled, modified and implemented to collect, describe, compare, contrast, classify, analyse and interpret the perceptions of teachers at six universities in China. The survey included 12 closed questions and 4 open questions. A pilot survey was conducted to facilitate testing of the survey instrument and a number of changes were made to the instrument. The revised survey was distributed to 510 academics and 293 surveys were collected.

The survey enabled the collection of information from a large number of teacher participants in different places. The survey results provided a variety of responses because the survey included open-ended responses from the participants. However, there were also some issues, which challenged the quality of the survey data. Firstly, since the survey had to be administered by other people in universities in other cities, it was difficult to control the process of conducting the survey. Secondly, in the interest of practicality, the information was limited to "yes/no" or short answers rather than "why" questions.

Interviews were conducted with nineteen teachers, six administrators and three policy makers from six universities across China. The document review process informed questions designed for the teacher survey and interviews, such as issues of curriculum, pedagogy and teachers' professionalism. The teacher interviews in turn provided the context for interviews with administrators and policy makers. In this sense, the docu-

${ }^{2}$ Bernstein (2000: p. 65) describes various temporal educational identities, which remains at the level of a mapping of possible positions; it is an "embryonic outline".

${ }^{3}$ Focus group interviews were considered culturally inappropriate (Hale, 2004), as teachers were unlikely to reveal their true feelings in front of their peers. ment analysis and the responses of interviews were coded to attempt to give some insights into the complicated picture of tertiary English teachers at university level in China and to answer the research questions

The semi-structured interview schedule was composed of 4 questions with 34 sub-questions and was designed to collect teacher perceptions. Following analysis of the teacher interviews, the semi-structured interview protocols were developed for administrators and policy makers with each tool being reviewed by academics working in the field for clarity, ambiguity and alignment with the research questions before they were translated into Chinese. Changes were made to the interview questions to address issues that arose following trials of each protocol. The revised interview consisted of a semi-structured schedule with opportunities for probing where necessary and for free response where the interviewees indicated the desire to go beyond the schedule. Interviews were digitally recorded and field notes were collected during this process. The advantage of the interview was that it allowed participants to introduce their own perspectives and to clarify their responses in a more discursive context.

The participants were identified in Harbin, Beijing, and Shanghai and selected according to different age, gender, institution, qualifications, experience, and working status. Participants generously gave an average time of more than an hour and a half of direct personal contact, which enabled the gaining of the forthright opinions of those working "at the coalface". To maintain anonymity, the identities of all participants have been coded as T (1-19) for teachers, A (1-6) for administrators and P (1-3) for policy makers.

Initial analysis of the interview data involved coding emergent themes and then, Maton's (2004) three concepts of "temporality", "autonomy" and "specialisation" were adopted to identify and interpret key relationships and interrelationships between policy and reality, teachers and the context in the social scientific analysis of textual data.

\section{Teachers' Responses to Eclecticism and Principled Eclecticism}

Teachers appear to have an inadequate understanding of the concept of principled eclecticism from College English Curriculum Requirements (2004). This can be seen in the result of the first question in the survey (Q1: To what extent are you familiar with the national college English syllabus?). It shows that $57.3 \%$ of teacher participants are very familiar with CECR (2004) while $31.1 \%$ of them knew "somewhat" of it. $11.6 \%$ of them did not know of it. However, when the interview participants were asked "In which way do you think the new curriculum impacts on your teaching?” two of them said "vocabulary is enlarged"; three of them mentioned that "we will make use of the computer-based model in teaching later". Half of the teachers did not answer this question. This might suggest that many teachers have not been made aware of the changes in the new curriculum or they might not have sufficient background to understand the implications of the introduction of CECR 2004 for them.

Teacher's understanding of the concepts of eclecticism and principled eclecticism for English teachers at university level in China seem to be blurred. This is also reflected in the results of the survey, as seen in answers to Questions 4 (What are your current approaches to your English teaching?) (See Table 1) 
Table 1.

Teachers' responses about their current approach to English teaching.

\begin{tabular}{ccccc}
\hline Grammar-translation & Communicative & Mixed methods & Missing data & Total \\
\hline $91(31.1 \%)$ & $46(15.7 \%)$ & $68(23.2 \%)$ & $88(30 \%)$ & $293(100 \%)$ \\
\hline
\end{tabular}

and Question 5 (Was there a change in your teaching approaches in the past few years?) (See Table 2 ).

Table 1 shows that, $31.1 \%$ of teachers used the traditional method; this might indicate that the teachers were lacking in confidence, in their ability to implement the new teaching model or that they perceived that a traditional teaching model was appropriate for their context. It also shows that $23.2 \%$ of teachers used eclectic approaches, whilst $30 \%$ did not answer the question. The fact that such a sizeable proportion of teachers (30\%) did not answer the question suggests that they might not have been sure of exactly what teaching methods they were using or possibly they did not recognise the terms used for the different teaching approaches.

The responses to Question 5 on whether there was a change in their teaching approaches in the past few years are in contradiction with the results of Question 4.

The results for Question 5 show that most (90.1\%) teachers claimed to have changed their teaching methods in the recent past, and that only $7.8 \%$ had not made any change. This figure implies that almost all teachers were trying new teaching methods, even though responses to Question 4 indicated that only $23.2 \%$ of them used eclectic approaches and $31.1 \%$ used traditional approaches. This issue will be explored in the interviews. These conflicting results could indicate that the teachers' understanding of pedagogical methodology may be variable. Along with the shift to computer-based learning, the change from a teacher-centred model to a student-centred philosophy radically challenges the inadequate teaching methodology of the teacher transmitting knowledge to students who are becoming active, independent learners and users of the language.

Teachers' ill-defined eclecticism and principled eclecticism was also explored in the interviews to clarify the interpretation of some of the survey results. Some comments from lecturers suggest that the pedagogy implied in CECR 2004 is of little relevance to their teaching, given the pressures of covering textbook content and examination demands. T12 at a university in Beijing, observed:

To be honest, I do not know that much about computer teaching. I use the CD-ROM for my teaching. For me, the teaching model is exam teaching, before the College English Test (Band 4/6), and textbook teaching after it.

Further evidence of eclectic teaching including textbook teaching and exam teaching were provided by $\mathrm{T} 1$, another Lecturer from Beijing:

...in terms of teaching method, I teach textbooks focused on basic language knowledge, based on my own methods, such as Grammar-Translation, or Audiolingualism in the first three semesters. In the final semester, my teaching focuses on College English Text (Band 4) by doing a large number of exer-

Table 2.

Teachers' responses about a change in their teaching approach in the past few years.

\begin{tabular}{cccc}
\hline Yes & No & Missing data & Total \\
\hline $264(90.1 \%)$ & $23(7.8 \%)$ & $6(2.0 \%)$ & $293(100.0 \%)$ \\
\hline
\end{tabular}

cises to help students pass CET4; the textbook is not used anymore.

These comments show that textbook teaching could be viewed as the predominant teaching approach since eleven teacher participants emphasised this point. This matches the result from Question 6 (Do you teach based on textbooks?), which indicates that $87 \%$ of teachers were dependent on the textbooks for their teaching. The comments above also shows the dominant position of the College English Test-Band 4 in helping shape the pedagogy in tertiary English teaching in China.

Other comments suggest that lecturers are not sure why they do what they are doing in their practical teaching. The comment below by T6, from a university in Harbin, indicates a willingness to adopt a student-centred approach, but a lack of understanding of how this might work:

I always adjust my teaching, because I have to find out what students really like. I help students remember more vocabulary, to increase their reading ability, by teaching them to see how it is formed and how to use them in context. I got to know this method from my students, because they often gave up English learning, because of the large vocabulary. I then put vocabulary and sentence patterns into translation. This is practical, because you cannot ignore Chinese meaning when you learn English.

Similarly, T9, a lecturer from Harbin, shows a desire to change, though his efforts demonstrate confusion, regarding what is meant by learner-centred pedagogy:

I want to change what I am doing, because it is not only for myself. I focus on the students' language ability. I did an experiment by adding one hour for listening each day. I asked the students to repeat what they listened to.

In addition, the administrators also noted the teachers' blurred understanding of pedagogy and the continued use of traditional methods. For instance, A6 in Harbin stated that:

Everybody knows that teachers teach vocabulary and grammar in their English teaching in our universities. This is what is known as "dumb and deaf English", which fails to make students communicate with others. The reason for such a failure is that teachers are not sure how to teach. We devote a lot of time teaching English, but it is not done in an effective way.

A1 from Shanghai pointed out that teachers were not guided and supported in "how to teach" by both the national curriculum as well as the university-based syllabus:

Principally, there should be something to interpret CECR 2004 further, to help teachers understand "what to teach" and "how to teach". However, in practical terms, the CECR and the university syllabus do not offer anything for this.

Moreover, policy-maker participants have concerns about the relationship between the policy and the implementation of the policy. P3, one of the members of the committee for CECR 2004 from Beijing, stated that he worried that teachers might not fully comprehend CECR 2004 because most of the lecturers

\footnotetext{
“"Dumb and deaf English”: stands for the unsatisfactory learning of English in China, in particular, at university level. It means that after many years of English language learning, students can neither understand English clearly nor speak English fluently.
} 
for English teaching at university level have backgrounds in English for literature and linguistics rather than English education.

However, P1, a policy-maker and key member of the committee for CECR 2004, pointed out that teachers' present understanding of pedagogy matches the current English teaching at university level.

Most teachers can be qualified for their present teaching, because Reading, Writing and Translation are taught as general English teaching. ... Additionally, College English Test is the main way to evaluate their teaching. Therefore, the present methods they are using are sufficient for them.

The comments of policy-makers above might help interpret the complication of current English teaching at university level in China. The first comment shows that the confusion of teachers towards principled eclecticism might come from their lack of background. The second comment indicates that since the main focus of current tertiary English teaching appears to be general English teaching, teachers' inadequate understanding of principled eclecticism is not relevant for them in implementing the national curriculum. All the responses from teachers, administrators and policy-makers in the data survey and interviews suggest conflicts between the policy and the reality.

\section{Policy versus Reality}

In terms of temporality, CECR 2004 mandates great changes in pedagogy, such as the new computer-teaching model (2004: p. 23) and two types of classroom teaching, which are required to remould the traditional teacher-centred approach. In reality, there is little evidence of change in the practices of the teachers, administrators and policy-makers on the ground. In most cases, teachers are confused by the lack of clarity of the computerteaching model and the two types of classroom teaching, what the teaching model is based on and how the model should be implemented. As a result, they are unsure themselves as to how to implement the model and so would have difficulty justifying their approach in terms of principled eclecticism. Although CECR 2004 requires a learner-centred approach, instead of a teacher-centred one, it does not explain what the teaching philosophy is in detail and does not provide any guidance about what this teaching philosophy means in the Chinese context, or how a learner-centred approach can be implemented. The push for the use of new technologies was not understood thoroughly as employing innovative techniques, but simply as a way to reduce the burden of large classes, as stated in the interview of an administrator (A6).

In terms of autonomy, CECR 2004 maintains that "it should not bare song" (2004: p. 2) which means the policy should offer teachers more autonomy in their practical teaching rather than to be restricted by the policy.

In reality, however, when teachers are lost and confused by the lack of explanation of the theoretical rational underpinning the technical teaching in CECR and little guidance as to which way such a model might be implemented, there might not be so-called autonomy in their selection between eclecticism and principled eclecticism. As a result, there remains a strong preference for teaching via textbooks in "what to teach", vocabulary and translation teaching with traditional methods or eclectic approaches in "how to teach" and a reliance on the College English Test in determining "what to assess".

In terms of specialisation, there is no evidence that the CECR policy has recognised teachers' current knowledge back- ground to implement the new teaching model since there is no specific training that has been designed or implemented that can help teachers change their behaviour in their classroom.

While teachers are eager to make change themselves, in reality, the requirement of the student centred approach and new technical teaching in the policy challenges teachers' current knowledge in terms of their current training in understanding curriculum and syllabus, their knowledge of principled eclecticism and computer teaching. Their continued reliance on textbook teaching and the College English Test mitigates against pedagogical change in English teaching at university level.

\section{Conclusion}

The gap between policy and reality is reflected in the differentiation between eclecticism and principled eclecticism in the context of tertiary English teaching in China. Using Maton's framework (2004a), analysis of the data collected shows that teachers are tending to focus on eclectic approaches in China, and their views indicate this is because of insufficient interpretation of policies, textbook teaching, College English Testoriented teaching, and their lack of knowledge of pedagogy. Principled eclecticism, in the context of China, should not be a simple configuration of different options. Instead, it should be a systematic decision based on a specific dynamic context. Principled eclecticism should be a complete understanding of all learning theories and related pedagogies in terms of the purpose and context of language learning, the needs of the language learners, how language is learned, and how and what teaching is all about (Harmer, 2003) in the context of general English teaching at university level.

In order to address these issues, there at two major initiatives that could be implemented.

1) Teacher access to targeted professional development to support their implementation of new pedagogical approaches.

2) Redrafting and remodelling of the policies concerning tertiary English teaching to incorporate the support and underlying explanations of the approaches needed to effectively interpret the CECR 2004 policy.

Additionally, in order to achieve these goals, the Ministry of Education could appoint a team with specialist knowledge and expertise in English language teaching theory and practice, to develop a coherent policy statement that is grounded in research and sensitive to the Chinese context. Then at least there would be a strong base to build teacher skills from and if such a statement should be supported by detailed documents providing practical guidance on how the syllabus can be implemented at the levels of the institution and the individual classroom then teachers might have the confidence necessary to embark on pedagogical change.

More practically, local provincial governments could organise or establish teachers' training centres in some universities to help teachers' to clarify their pedagogy and guide them to implement the policy properly and effectively.

\section{Acknowledgements}

I would like to acknowledge the support of Professor B. Harper in representing the ideas in this paper.

\section{References}

Bernstein, B. (2000). Class, codes and control, volume V: Pedagogy, 
symbolic control and identity: Theory, research, critique. (Revised edition). Oxford: Roman \& Little field.

Bourdieu, P. (1993). The field of cultural production. Cambridge: Polity.

Brown, H. (2002). English language teaching in the "post-method" era: Toward better diagnosis, treatment, and assessment. In J. Richards and W. Renandya (Eds.), Methodology in Language Teaching: An Anthology of Current Practice (pp. 9-18). Cambridge: Cambridge University Press. doi:10.1017/CBO9780511667190.003

Gao, L. L. (2010). Policy challenges for university English teachers in China: Beyond the obvious. Berlin: VDM Verlag Dr. Muller.

Hale, S. (2004). The discourse of court interpreting: Discourse practices of the law, the witness, and the interpreter. Amsterdam, Philadelphia: J. Benjamins Pub. Co.

Harmer, J. (2003). Popular culture, methods, and context. ELT Journal, 57, 288-294. doi:10.1093/elt/57.3.288

Jia, G. (2004). The new trends of language teaching approaches. Foreign Language World, 104, 74-78.

Kumaravadivelu, B. (2001). Toward a postmethod pedagogy. TESOL Quarterly,35, 537-560. doi:10.2307/3588427

Larsen-Freeman, D. (2000). Techniques and principles in language teaching (teaching techniques in english as a second language). (2nd ed.). Oxford: Oxford University Press.

Liang, A., \& Gao, H. (2004). On inquiring teaching model. Journal of Basic English Education, 6, 18-21.

Liu, R., \& Dai, M. (2003). Study on the present college English teaching and its development in China. Beijing: Foreign Language Teaching and Research Press.

Luo, L., He, F., \& Yang, F. (2001). Introduction to comprehensive teaching methods in college English teaching. Foreign Language
World, 4, 5-9.

Ma, Z. (1998). The realization of CLT in grammar teaching in college English. Foreign Language World, 69, 44-46.

Marsh, C. (2000). Innovation and change. Handbook for beginning teachers. (2nd ed.). NSW: Pearson Education.

Maton, K. (2004a). The field of higher education: A sociology of reproduction, transformation, change and the conditions of emergence for cultural studies. Ph.D. Thesis, Cambridge: Cambridge University Press.

Mellow, D. (2002). Toward principled eclecticism in language teaching: The two-dimensional model and the centring principle. Teaching English as a Second Language Electronic Journal, 5, A-1.

Ministry of Education of the People's Republic of China (2004). College English curriculum requirements (for trial). Beijing: Tsinghua University Press.

Nunan, D. (1991). Language teaching methodology. Sydney: PrenticeHall.

Pennycook, A. (1989). The concept of method, interested knowledge, and the politics of language teaching. TESOL Quarterly, 23, 589618. doi:10.2307/3587534

Wang, Y. (2001). Eclecticism in foreign language teaching. Foreign Language World, 2, 25-28.

Yan, X., Zhou, Z., \& Dai, P. (2007). Principled eclecticism in college English teaching in China. Asian EFL Journal, 17, 1-38.

Yi, L. J., \& Liu, X. P. (2004). Introduction to genre-approach in Australia. Journal of Xi'an International Studies University, 12, 33-35.

Ying, H., He, L., \& Zhou, S. (1998). The reform of college English teaching: A learner-centred thematic teaching model. Foreign Language Teaching and Research, 4, 22-26. 